\title{
HBV X protein-based therapeutic vaccine accelerates viral antigen clearance by mobilizing monocyte infiltration into the liver in HBV carrier mice
}

Jau-Hau Horng ${ }^{1}$, Wei-Hsiang Lin², Chang-Ru Wu' ${ }^{1}$ You-Yu Lin ${ }^{3}$, Li-Ling Wu ${ }^{4}$, Ding-Shinn Chen ${ }^{3,5,6}$ and Pei-Jer Chen ${ }^{1,3,5,6^{*}}$ (ID

\begin{abstract}
Background: Hepatitis B virus (HBV) persistently infected about 250 million people worldwide, and a curative treatment remains an unmet medical need. Among many approaches to treat chronic hepatitis $B(C H B)$, therapeutic vaccines have been developed for two decades, but none have yielded promising results in clinical trials. Therefore, dissection of HBV clearance mechanisms during therapeutic vaccination in appropriate models, which could give rise to new curative therapies, is urgently needed. Growing evidence indicates that prolonged and intensive exposure of antigen-specific T cells to viral antigens is a major cause of T cell exhaustion, and decreases anti-HBV immunity efficacy of therapeutic vaccination. HBV X protein (HBX) is expressed at low levels, and the understanding of its immunogenicity and potential in therapeutic CHB vaccines is limited.

Methods: HBV genome sequences from CHB patients were cloned into a PAAV plasmid backbone and transfected into immunocompetent mouse hepatocytes through hydrodynamic injection. Mice carrying $>500 \mathrm{IU} / \mathrm{mL}$ serum HBV surface antigen (HBs) for more than 4 weeks were considered HBV carriers mimicking human $\mathrm{CHB}$ and received 3 doses of weekly HBx vaccine by subcutaneous immunization. Serum HBV clearance was evaluated by monitoring serum HBs and HBV-DNA titers. Residual HBV in the liver was evaluated by western blotting for HBV core antigen. The splenic antigen-specific $T$ cell response was quantified by a 15-mer overlapping peptide-stimulated interferon- $\gamma$ enzyme-linked immunospot assay. Blood and hepatic immune cells were quantified by flow cytometric analysis.

(Continued on next page)
\end{abstract}

\footnotetext{
* Correspondence: peijerchen@ntu.edu.tw

${ }^{1}$ Graduate Institute of Microbiology, National Taiwan University College of Medicine, No. 1 Jen Ai Road Section 1, Taipei, Taiwan (R.O.C.)

${ }^{3}$ Graduate Institute of Clinical Medicine, National Taiwan University College of Medicine, No. 1, Jen Ai Road Section 1, Taipei, Taiwan (R.O.C.)

Full list of author information is available at the end of the article
}

(c) The Author(s). 2020 Open Access This article is licensed under a Creative Commons Attribution 4.0 International License, which permits use, sharing, adaptation, distribution and reproduction in any medium or format, as long as you give appropriate credit to the original author(s) and the source, provide a link to the Creative Commons licence, and indicate if changes were made. The images or other third party material in this article are included in the article's Creative Commons licence, unless indicated otherwise in a credit line to the material. If material is not included in the article's Creative Commons licence and your intended use is not permitted by statutory regulation or exceeds the permitted use, you will need to obtain permission directly from the copyright holder. To view a copy of this licence, visit http://creativecommons.org/licenses/by/4.0/ The Creative Commons Public Domain Dedication waiver (http://creativecommons.org/publicdomain/zero/1.0/) applies to the data made available in this article, unless otherwise stated in a credit line to the data. 


\begin{abstract}
(Continued from previous page)
Results: Our HBx-based vaccine induced systemic HBx-specific $\mathrm{CD} 4^{+}$and $\mathrm{CD} 8^{+} \mathrm{T}$ cell responses in HBV carrier mice and demonstrated significant HBs and HBV-DNA elimination. The protective effect persisted for at least 30 days without additional booster immunization. Different infiltrating myeloid cell subsets, each with distinctive roles during immune-mediated HBV clearance, were found in the liver of vaccinated mice. During vaccine therapy, inflammatory monocyte depletion resulted in sustained HBV clearance inhibition, whereas phagocytic monocytederived macrophage and Kupffer cell elimination resulted in only transient inhibition of vaccine-induced HBV clearance.

Conclusions: We report the potential role of HBx as a major immunogen in an HBV therapeutic vaccine and the significance of a liver-infiltrating monocyte subset during hepatic viral clearance.
\end{abstract}

Keywords: Chronic hepatitis B, Immunotherapy, Hepatic innate immunity, Myeloid cell

\section{Background}

Despite decades of active vaccination, chronic hepatitis $\mathrm{B}(\mathrm{CHB})$ remains highly prevalent, with the World Health Organization estimating there are 250 million carriers worldwide. This results in a heavy disease load of hepatitis B virus (HBV)-related, end-stage liver diseases and a high death toll. At present, there are only two approved treatments for CHB: nucleot(s)ide analogs and pegylated interferon (IFN). Both treatments effectively inhibit viral replication but have limited efficacy in removing persistent viral genomes from infected hepatocytes or in clearing HBV surface antigen (HBs) from the serum. Therefore, exploring new curative therapies and elucidating their mechanisms in appropriate animal models are urgently needed.

$\mathrm{T}$ cell exhaustion is commonly observed in $\mathrm{CHB}$ patients and is characterized by dysfunctional HBs-, HBV core antigen $(\mathrm{HBC})-$, and polymerase-specific $\mathrm{T}$ cells that express multiple immune inhibitory receptors, such as programmed cell death protein 1 [1-3]. Recent studies have reported this dysfunction to extend to HBs-specific B cells, which also display surface markers of exhaustion and defective antibody production in CHB patients [4]. These adaptive immunity deficiencies in $\mathrm{CHB}$ patients are the major cause of the host's inability to remove HBVinfected hepatocytes and clear HBs from the blood.

Currently, curative immune-therapeutic strategies for $\mathrm{CHB}$, including therapeutic vaccination, immune checkpoint inhibitors, oral Toll-like receptor agonists, and even engineered $\mathrm{T}$ cell therapy, are focused on restoring or enhancing host cytotoxic $\mathrm{T}$ cell activity to destroy HBV-infected hepatocytes [5]. Several studies have reported promising results, but the approaches require further clinical trials. Among these strategies, therapeutic vaccination is one of the simplest and most straightforward strategies. However, despite more than 20 years of development with some vaccines entering clinical trials, no satisfactory results have been obtained thus far [6]. In one recent clinical trial, the GS-4774 vaccine (a fusion antigen composed of $\mathrm{HBs}, \mathrm{HBc}$, and a partial HBV X protein $(\mathrm{HBx})$ sequence) showed modest increases in HBs- and HBc-specific $\mathrm{CD}^{+} \mathrm{T}$ cell numbers with an improved cytokine secretion ability in peripheral blood mononuclear cells (PBMCs), and exhausted T cell numbers were also reduced in the total $\mathrm{CD} 8^{+} \mathrm{T}$ cell pool [7]. Nevertheless, the vaccine did not recover sufficient virus-specific $\mathrm{CD} 4^{+} \mathrm{T}$ cells or $\mathrm{B}$ cells or enhance innate immune responses and thus failed to reduce the circulating HBs level. Subverting the host's tolerogenic status to $\mathrm{HBV}$ antigens remains the main challenge in developing a curative therapy.

One unique feature of $\mathrm{CHB}$ is the excessive levels of viral antigens (HBs, $\mathrm{HBc}$ and $\mathrm{HBV}$ e antigen) in both infected hepatocytes and the circulation. Such antigens have been proposed as tolerance-inducing antigens [8]. It is well documented in a chronic lymphocytic choriomeningitis virus infection model that persistent highlevel viral antigen exposure through somatic cells results in antigen-specific $\mathrm{T}$ cell exhaustion $[9,10]$. It was also reported that in another liver-specific model, a high antigen expression level in hepatocytes largely suppresses hepatic-primed $\mathrm{CD}^{+} \mathrm{T}$ cell function in the liver [11]. Thus, to reduce the HBV antigen load, neutralizing antibodies, RNA interference, and/or nucleic acid polymers have been suggested as combination treatments for HBV immunotherapy [12]. We hypothesize that targeting viral proteins expressed at low levels in hepatocytes has advantages over targeting the abundant ones in restoring the antigen-specific $\mathrm{T}$ cell function in the liver. $\mathrm{HBx}$ is a prime therapeutic candidate because it controls HBV gene expression and replication but is expressed at low levels during natural infection [13, 14]. While most current HBV therapeutic vaccines usually focus on abundant HBV structural proteins, such as HBs and $\mathrm{HBc}$, as the major immunogens [6], HBx may actually be a more suitable immunogen candidate owing to its low expression levels. Here, we propose using the lowexpressed molecule $\mathrm{HBx}$ as a therapeutic vaccine antigen as an alternative method to rejuvenate anti-HBV adaptive immunity in CHB. The previously mentioned GS- 
4774 vaccine failed to increase $\mathrm{HBx}$-specific $\mathrm{T}$ cell numbers in CHB patients [7], possibly due to its use of a partial $\mathrm{HBx}$ sequence [15]. Therefore, the potential of fulllength $\mathrm{HBx}$ in therapeutic vaccines cannot be overlooked.

The liver is considered a tolerogenic organ that suppresses $\mathrm{T}$ cell functions in an antigen-independent manner and maintains its immunosuppressive environment via multiple mechanisms mediated through resident nonparenchymal cells (NPCs) [16, 17]. This tolerogenic liver environment further heightens the barrier to $\mathrm{CHB}$ immunotherapy. Hence, the regulation of liver-resident immunity is another important issue to consider in designing a successful curative therapy. Modulation of the liver-resident immune environment, such as the induction of intrahepatic myeloid cell aggregates for $\mathrm{T}$ cell population expansion, facilitates HBV immune clearance in mouse models $[18,19]$. The ultimate goal of HBV immunotherapy is to restore sufficient anti-HBV immunity in both the innate and adaptive arms to functionally cure $\mathrm{CHB}$ while overcoming $\mathrm{T}$ cell exhaustion and the tolerogenic liver environment. In the current study, we propose an $\mathrm{HBx}$-based therapeutic vaccine and evaluate its effect and possible mechanisms with an established immunocompetent HBV-persistent mouse model.

\section{Methods}

\section{Animals}

Male CBA/CaJ or C57BL/6 J mice ( $6 \sim 8$ weeks old) were purchased from the National Laboratory Animal Center (Taipei, Taiwan). Mice were housed in an animal biosafety level 2 facility with $<5$ mice per cage in a temperature-controlled room $\left(22 \pm 2{ }^{\circ} \mathrm{C}\right)$ with a 12 -h light/dark cycle.

\section{pAAV/HBV1.2 plasmid construct and a hydrodynamic HBV} transfection mouse model

A 1.2-fold over-length complete HBV genome sequence isolated from $\mathrm{CHB}$ patient serum was cloned into a pAAV plasmid backbone, namely, pAAV/HBV1.2, as described elsewhere [20]. The plasmid DNA was prepared with Endofree Maxiprep kits (QIAGEN, Hilden, Germany). A total of $10 \mu \mathrm{g}$ of pAAV/HBV1.2 plasmid was dissolved in $8 \%$ mouse body weight-equivalent phosphate-buffered saline (PBS) and injected via the mouse tail vein within $5 \mathrm{~s}$. The serum $\mathrm{HBs}$ titer was monitored after day 28 post-injection. Animals with a serum $\mathrm{HBs}$ titer $>500 \mathrm{IU} / \mathrm{mL}$ were considered stable HBV carriers.

\section{Preparation and administration protocol for the vaccine} formulation

RAP1-HBx and RAP1-E7 were constructed by fusing the $\mathrm{HBx}$ or human papillomavirus E7 protein (HPV-
E7) sequence, respectively, to a Pseudomonas Exotoxin A (PE-A) mimicry sequence to enhance immunogenicity (Supplementary Figure 1) [21]. Both fusion proteins were produced with the Escherichia coli expression system (TheVax Genetics Company, Taipei, Taiwan). TVGV-HBx and TVGV-E7 were obtained by mixing $100 \mu \mathrm{g}$ of RAP1-HBx or RAP1-E7 protein, respectively, with $20 \mu \mathrm{g}$ of $\mathrm{CpG}$ oligodeoxynucleotides (CpG-ODN; TheVax Genetic Company) in $50 \mu \mathrm{L}$ of PBS. The HPV-E7-containing vaccine served as an antigen specificity control for the $\mathrm{HBx}$ containing vaccine. Vaccine formulations were diluted in PBS if a lower vaccination dose was required. The trace endotoxin level in each vaccine was tested with an endotoxin quantification kit (Lonza, Basel, Switzerland). The total endotoxin quantity per injection was less than $10 \mathrm{EU}$. Recombinant $\mathrm{HBc}$ (rHBc; Xiamen University, Xiamen, China) and thioredoxinfused recombinant $\mathrm{HBx}(\mathrm{rHBx}$; TheVax Genetics Company) were produced with the Escherichia coli expression system. The rHBx-based vaccine was used in a comparative experiment with $\mathrm{rHBc}$ to prevent the possible bias caused by the immunostimulatory PE-A mimicry sequence. Trace endotoxin in protein preparations was removed with Pierce high-capacity endotoxin removal columns (Thermo Fisher Scientific, Waltham, MA, USA). The $\mathrm{rHBc}$ and $\mathrm{rHBx}$ vaccine preparation and administration protocols were the same as those described previously.

Extraction and quantification of serum and liver HBV-DNA Serum HBV-DNA was extracted with a MagNA Pure LC total nucleic acid isolation kit (Roche, Basel, Switzerland) according to the manufacturer's protocol. Total liver DNA was extracted by using a Gentra Puregene Tissue kit (QIAGEN). HBV-DNA was quantified by quantitative polymerase chain reaction (QPCR) on a LightCycler instrument (Roche). The primer set used for amplification had the sequences $5^{\prime}$ CCGATCCATACTGCGGAAC-3' and 5'-GCAGAG GTGAAGCGAAGTGCA-3'. The fluorescently labeled hybridization probes had the sequences $5^{\prime}$-LCRed640-TCTGTGCCTTCTCATCTGCCGGACC-PH-

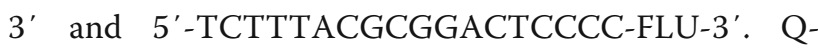
PCR was performed with the following conditions: denaturation at $95^{\circ} \mathrm{C}$ for $10 \mathrm{~min}$, followed by 45 cycles of denaturation at $95^{\circ} \mathrm{C}$ for $3 \mathrm{~s}$, annealing at $53^{\circ} \mathrm{C}$ for $10 \mathrm{~s}$, and extension at $72{ }^{\circ} \mathrm{C}$ for $16 \mathrm{~s}$. A standard calibration curve was derived with a serially diluted plasmid containing the HBV genotype $\mathrm{C}$ sequence.

\section{Serum viral biomarker analysis}

Mouse whole blood was collected in a plastic microcentrifuge tube and centrifuged at $13,000 \times \mathrm{g}$ to obtain the 
serum. The serum was diluted 10-fold in PBS and then analyzed with the following methods: HBs was analyzed with an Elecsys HBsAg II kit (Roche; Fig. 1a) or Architect HBsAg QT assay (Abbott, Lake Forest, IL, USA; Figs. 1c, 2a, 3e, 4a, 5c and d); anti-HBs antibodies were analyzed with an Elecsys Anti-HBs II kit (Roche); and anti-HBc antibodies were analyzed with an Elecsys AntiHBc II kit (Roche).

\section{Western blotting}

Total liver lysates were prepared by homogenizing 50 $\mathrm{mg}$ of liver tissue in $1 \mathrm{~mL}$ of T-PER ${ }^{\mathrm{ma}}$ reagent supplemented with a phosphatase and protease inhibitor cocktail (Thermo Fisher Scientific). The lysates were cleared by centrifugation at $13,000 \times \mathrm{g}$ for $15 \mathrm{~min}$. A total of $90 \mu \mathrm{g}$ of liver protein lysate was separated by $12 \%$ sodium dodecyl sulfate polyacrylamide gel electrophoresis
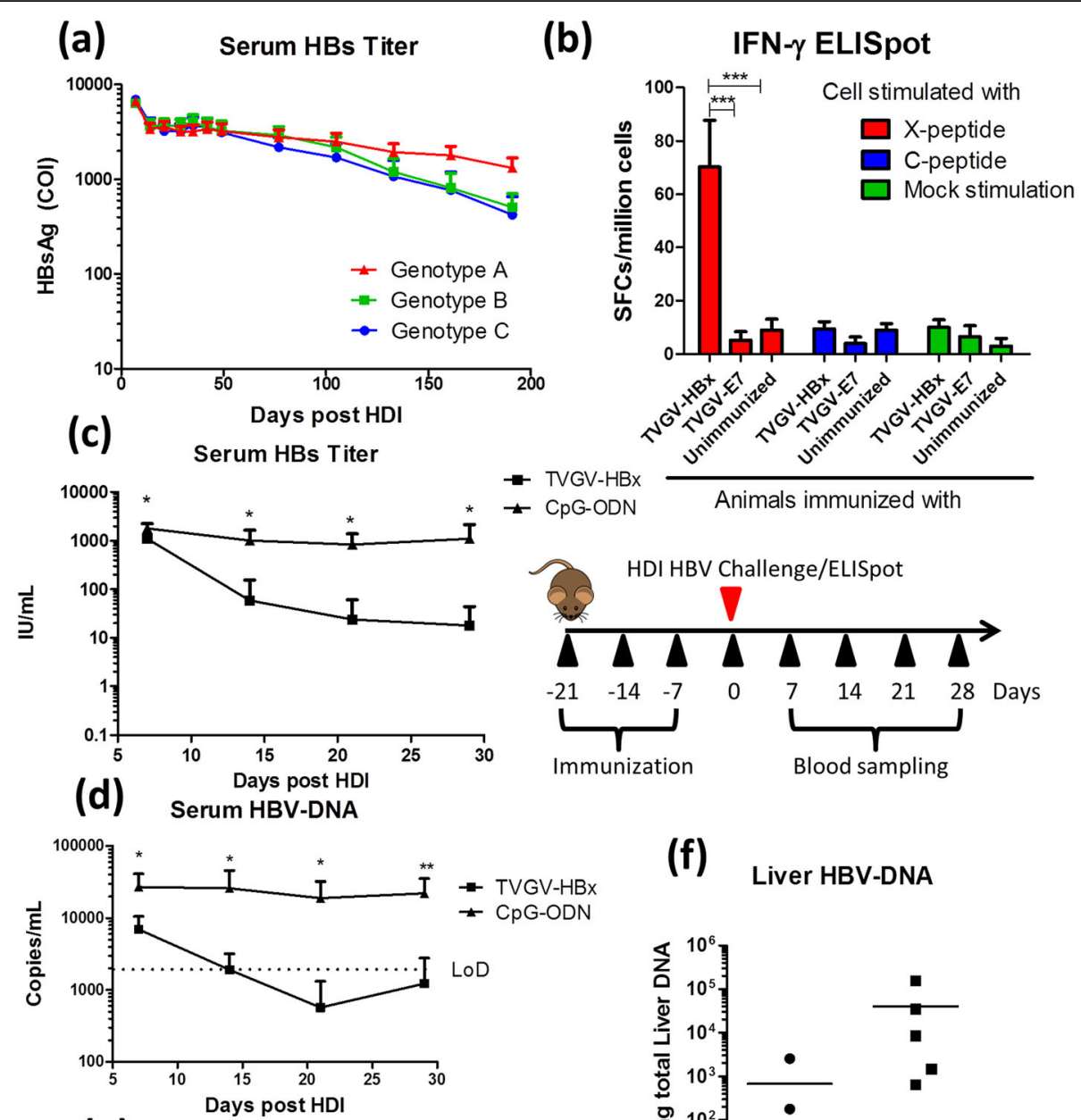

(e)
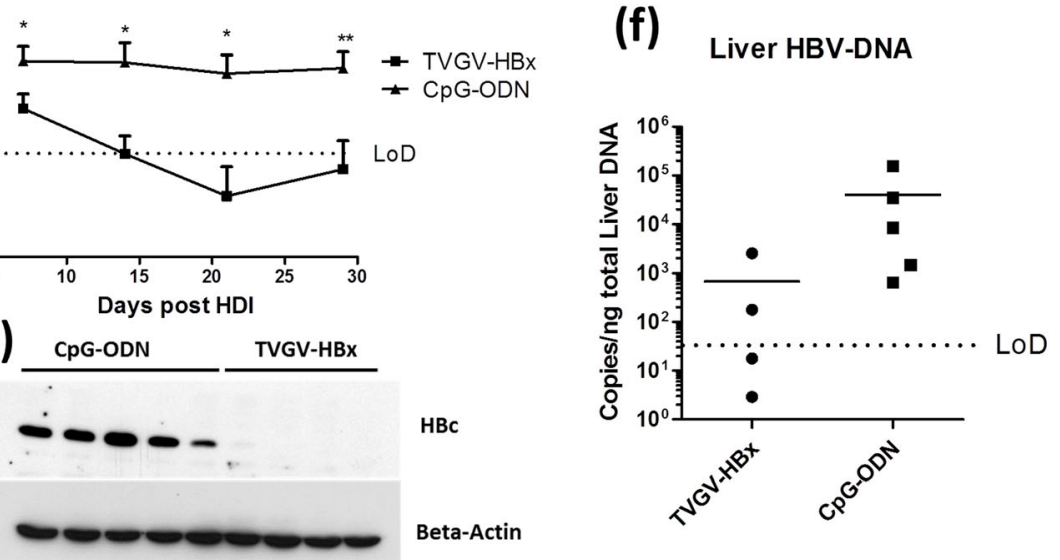

Fig. 1 TVGV-HBx exerts a protective function against hydrodynamic HBV exposure in persistence-prone CBA/CaJ mice. a Naïve CBA/CaJ mice ( $N=9)$ received hydrodynamic injection of $10 \mathrm{\mu g}$ of different genotypes of the pAAV/HBV1.2 plasmid on day 0. Blood samples were collected at the indicated time points, and the serum HBs titers are shown. $\mathbf{b}$ Naiive CBAVCaJ mice $(\mathrm{N}=4)$ received TVGV-HBx or TVGV-E7 or remained untreated on days 0,7 and 14 . Splenocytes were collected on day 21 and subjected to an IFN- - ELISpot assay. c-f Naïve CBAVCaJ mice ( $N=4 \sim 5)$ received TVGV-HBx or CpG-ODN immunization every 7 days for 3 consecutive weeks. Mice received HDI transfection with $10 \mu \mathrm{g}$ of pAAV/HBV1.2 plasmid one week after the last immunization. Mouse serum was sampled on days 7, 14, 21, and 28 after HDI transfection. Liver samples were collected at the endpoint of the experiment. c Serum HBs titers were determined. $\mathbf{d}$ Serum HBV-DNA was detected. e Liver HBC was detected by western blotting. $\mathbf{f}$ Liver HBV-DNA was detected. Statistics: Student's t-test. ${ }^{*}, p<0.05 ;{ }^{* *}, p<0.01 ;{ }^{* * *}, p<$ 0.001; COl, cut-off index; LoD, limit of detection; SFCs, spot-forming cells 


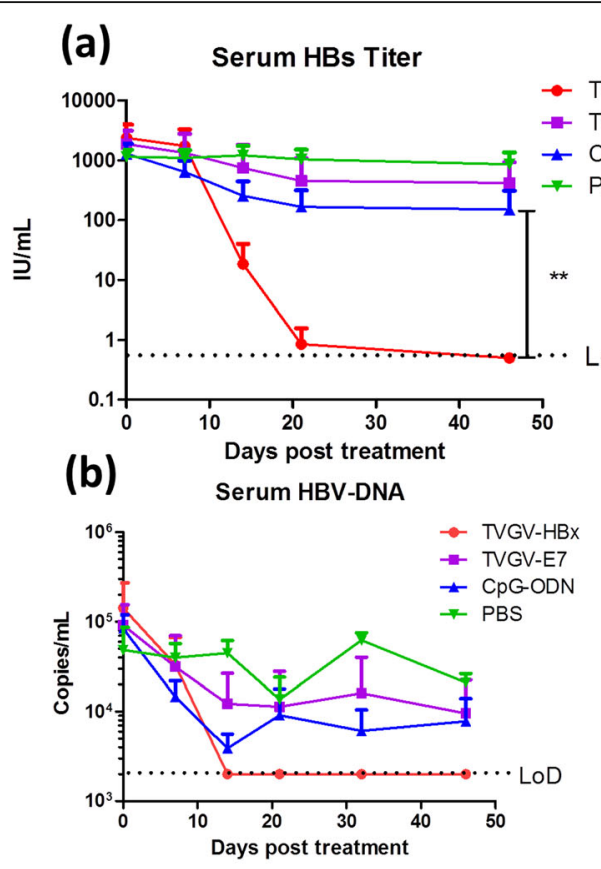

(d)

(c)

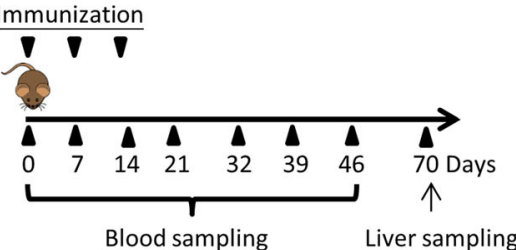

Anti-HBs Titer
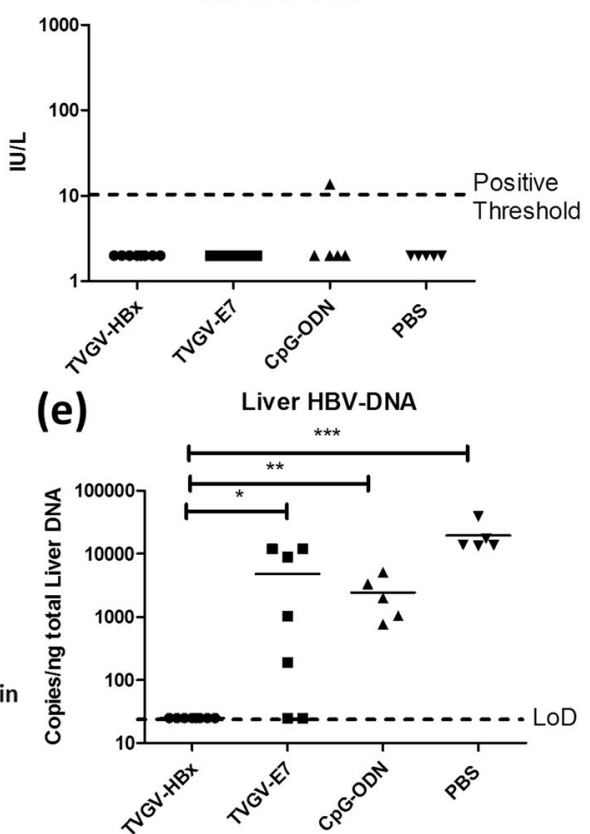

Fig. 2 TVGV-HBx exerts therapeutic function in HBV carrier mice. HBV carrier mice ( $N=5 \sim 8)$ received TVGV-HBx, TVGV-E7, CpG-ODN alone or PBS on days 0,7 and 14. Mouse serum was sampled on days 0,7, 14, 21,32, 39 and 46, and liver samples were collected on day 70. a Serum HBs titers were determined. b Serum HBV-DNA was detected. c Serum anti-HBs titer on day 39. d Liver HBc was detected by western blotting. e Liver HBV-DNA was detected. The value of the undetectable Q-PCR sample was assigned as the detection limit for plotting. Statistics: Student's $t$-test. *, $p<0.05 ;{ }^{* *}, p<0.01 ;{ }^{* * *}, p<0.001 ;$ LoD, limit of detection

and transferred to a PVDF membrane. The membrane was blocked with $5 \%$ nonfat milk for $1 \mathrm{~h}$ at room temperature. The membrane was probed for $\mathrm{HBc}$ with a rabbit anti-HBc polyclonal antibody (clone P3-NP, produced in our laboratory) overnight at $4{ }^{\circ} \mathrm{C}$. An antimouse beta-actin antibody (Sigma-Aldrich, St. Louis, MO, USA) served as an internal control. Protein signals were visualized with an appropriate horseradish peroxidase-conjugated secondary antibody (Bio-Rad, Hercules, CA, USA) and enhanced chemiluminescence substrate (Bio-Rad).

\section{IFN- $\gamma$ enzyme-linked immunospot assay}

Mouse splenocytes were collected by mincing the spleen through 70- $\mu$ m nylon mesh. Red blood cells were lysed by
ACK lysis buffer (Thermo Fisher Scientific). In the ex vivo $\mathrm{T}$ cell-depletion experiment, splenocytes were further labeled with a phycoerythrin-conjugated antiCD4 antibody or an APC-conjugated CD8-specific antibody (BioLegend, San Diego, CA, USA). Fluorochrome-labeled cells were then depleted with anti-phycoerythrin or anti-APC IMAG-magnetic microbeads (BD Bioscience, San Jose, CA, USA) according to the manufacturer's protocol. The enzymelinked immunospot (ELISpot) assay was conducted by using the Mouse IFN- $\gamma$ ELISpot Kit (BD Bioscience) according to the manufacturer's protocol. A total of 0.3 million splenocytes were seeded in an anti-IFN- $\gamma$ antibody-coated PVDF plate. The cells were cultured with $10 \%$ fetal bovine serum (FBS) supplemented 
(a) IFN- $\gamma$ ELISpot (b)
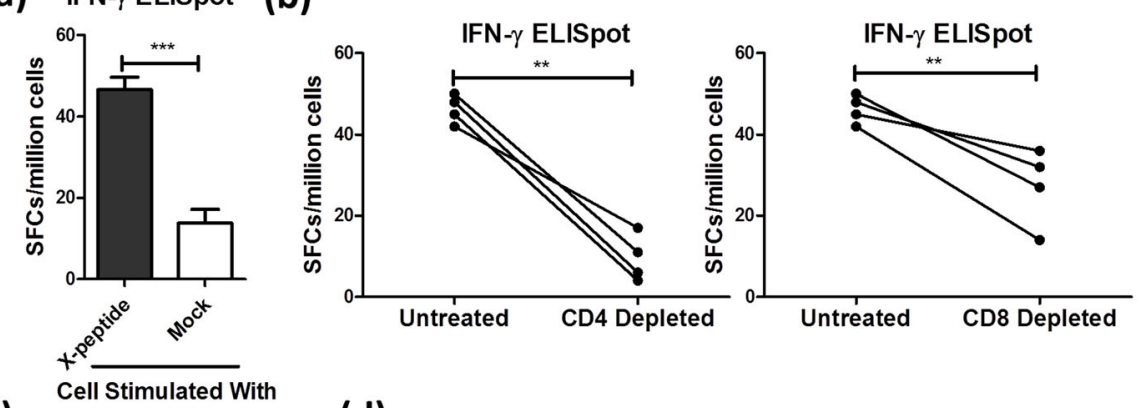

(c)

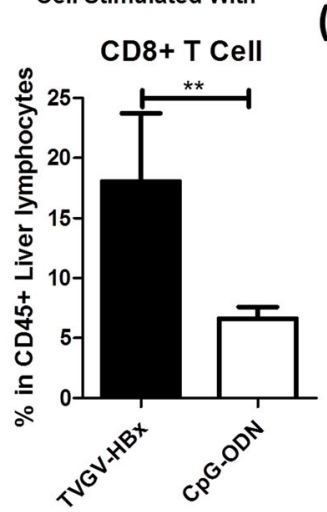

(d)

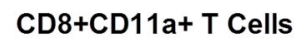

CD8+CD11a-T Cells
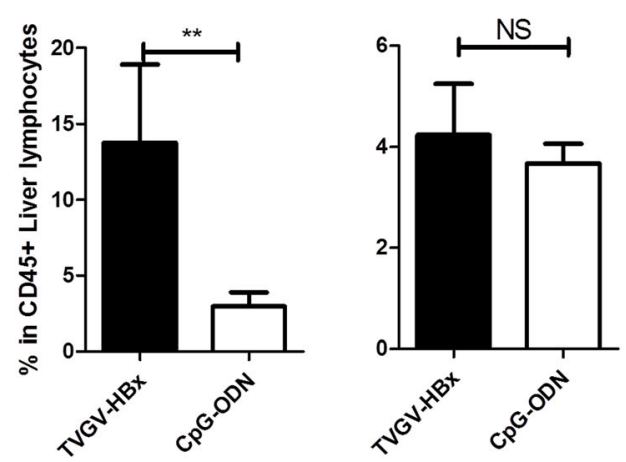

(e)

Serum HBs Titer

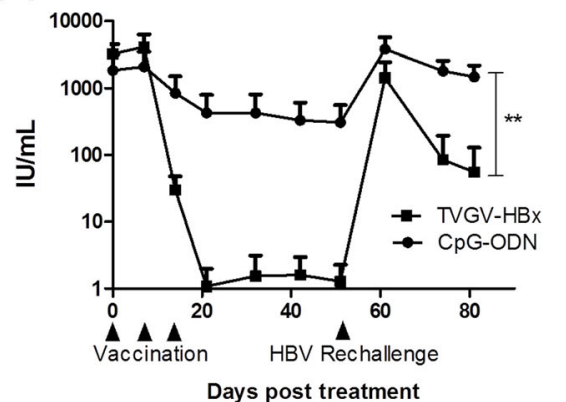

(f)

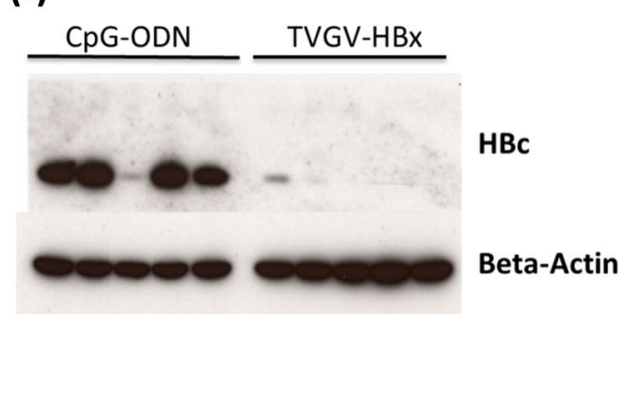

Fig. 3 TVGV-HBx induces an HBX-specific T cell response and posttreatment immune memory in HBV carrier mice. a-b HBV carrier mice $(N=4)$ received TVGV-HBx on days 0,7 and 14 . Splenocytes were isolated at day 21 and subjected to ex vivo $C D 4^{+}$or $C D 8^{+} T$ cell depletion or left untreated. Splenocyte preparations were subjected to 15-mer overlapping HBx peptide-stimulated IFN- $\gamma$ ELISpot assays. a Normalized spot counts of untreated splenocytes. b Pairwise comparative results for untreated splenocytes versus $\mathrm{CD} 4^{+}$cell- or $\mathrm{CD} 8^{+}$cell-depleted splenocytes. $\mathbf{c}-\mathbf{d} \mathrm{HBV}$ carrier mice $(\mathrm{N}=3$ $\sim 4$ ) received TVGV-HBx or CpG-ODN alone on days 0 and 7. Intrahepatic lymphocytes were isolated on day 10. Isolated cells were analyzed by flow cytometry to evaluate $T$ cell subpopulations. c Frequency of liver $C D 8^{+} T$ cells among total $C D 45^{+}$intrahepatic lymphocytes. $\mathbf{d}$ Frequency of liver $\mathrm{CD} 11 \mathrm{a}^{+} \mathrm{CD} 8^{+}$and $\mathrm{CD} 11 \mathrm{a}^{-} \mathrm{CD} 8^{+} \mathrm{T}$ cells among $\mathrm{CD} 5^{+}$intrahepatic lymphocytes. e-f HBV carrier mice $(\mathrm{N}=5)$ were immunized with TVGV-HBx or CpGODN on days 0,7 and 14 and rechallenged with $\mathrm{HDI}$ of $10 \mu \mathrm{g}$ of pAAV/HBV1.2 plasmid on day 53. Blood samples were collected at the time points indicated on the plots, and liver samples were collected on day 84. e Serum HBs titer were determined. $\mathbf{f}$ Liver HBc was detected by western blotting. Statistics: Student's $t$-test. ${ }^{* *}, p<0.01 ;{ }^{* *}, p<0.001$; NS, not significant; SFCs, spot-forming cells

RPMI-1640 medium, and then stimulated with synthetic 15-mer overlapping peptide pools (JPT Peptide Technologies, Berlin, Germany) spanning the whole protein sequence at the concentration of $1 \mu \mathrm{g} / \mathrm{mL}$ per peptide for $18 \mathrm{~h}$. Spots were visualized with an AEC substrate kit (BD Bioscience) according to the manufacturer's protocol. Spot counting and analysis were conducted with an immunospot analyzer (Cellular Technology, Cleveland, OH, USA).
Mouse liver lymphoid and myeloid cell isolation

For mouse liver-resident lymphoid cell isolation, the liver was perfused with $5 \mathrm{~mL}$ of PBS to remove blood cells. The liver was isolated and then minced by passage through a $100-\mu \mathrm{m}$ nylon mesh (BD Bioscience) to obtain a liver cell suspension. The cell suspension was centrifuged at $50 \times \mathrm{g}$ twice to remove hepatocytes, and the crude lymphoid cells in the supernatant were pelleted by $300 \times$ g centrifugation. The cell pellet was re-suspended 


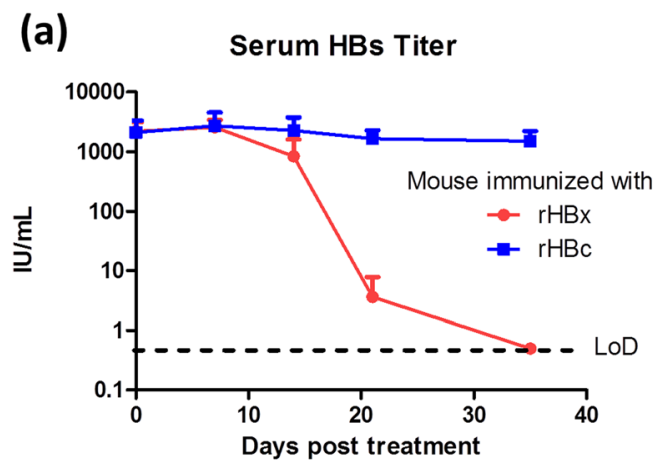

(c)

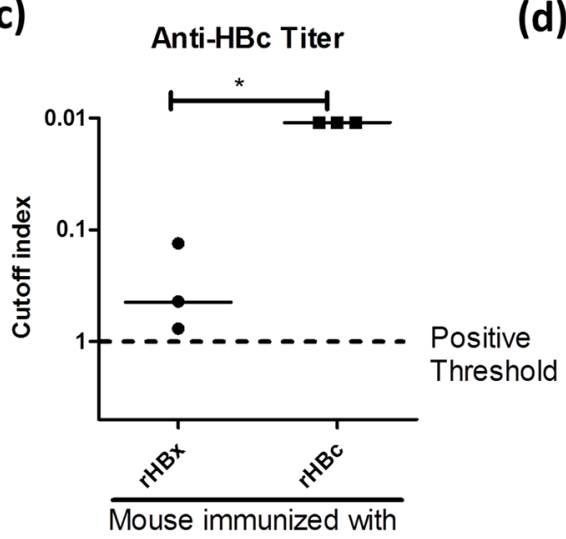

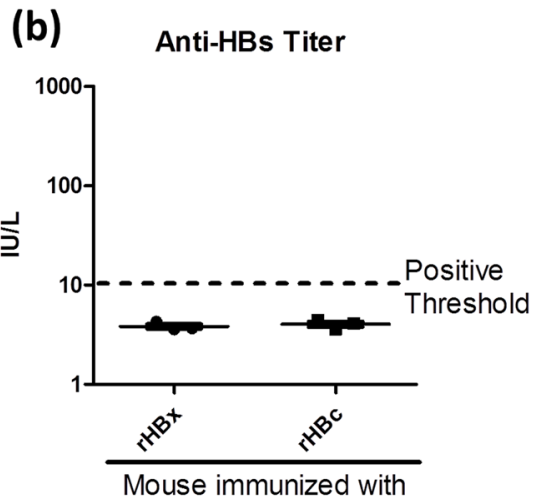

IFN- $\gamma$ ELISpot

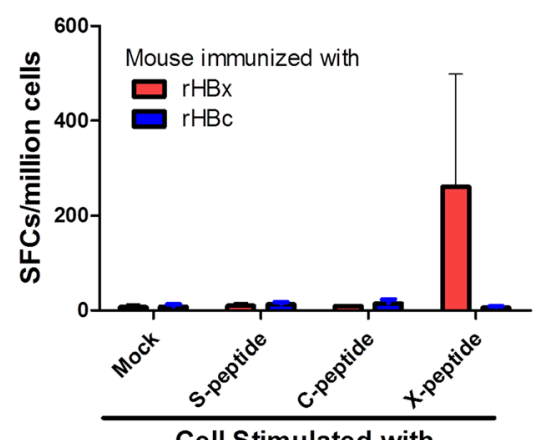

Fig. 4 Comparison of the immunogenicity of HBV core antigen and that of HBV X protein. a-c HBV carrier mice $(\mathrm{N}=3)$ received vaccination with $3.125 \mu \mathrm{g}$ of r $\mathrm{HBC}$ or $\mathrm{rHBx}$ supplemented with $0.625 \mu \mathrm{g}$ of $\mathrm{CpG}-\mathrm{ODN}$ on days 0,7 and 14 . Mouse serum was sampled on days $0,7,14,21$ and 35 . (a) Serum HBs titers were determined. b Serum anti-HBs antibody titer on day 35. c Serum anti-HBc antibody titer on day 35. Lower values represent higher antibody production because the anti-HBC assay is a competition assay. $\mathbf{d}$ HBV carrier mice $(\mathrm{N}=3 \sim 4$ ) received vaccination with $6.25 \mu \mathrm{g}$ of $\mathrm{rHBC}$ or $\mathrm{rHBx}$ supplemented with $1.25 \mu \mathrm{g}$ of $\mathrm{CpG}-\mathrm{ODN}$ on days $0,7,14$ and 22. Mice were boosted once with the same dose 7 days before splenocyte isolation. Splenocytes were separately stimulated with HBx-, HBs-, or HBC-derived 15-mer overlapping peptide pool and subjected to an IFN- $\gamma$ ELISpot assay. The result was normalized to the spot counts per million cells. LoD, limit of detection; SFCs, spot-forming cells

in $4 \mathrm{~mL}$ of $40 \%$ Percoll solution (GE Healthcare, Chicago, IL, USA), which was then layered on top of $4 \mathrm{~mL}$ of $70 \%$ Percoll solution. The gradient was separated by $1200 \times g$ centrifugation at $25^{\circ} \mathrm{C}$ for 20 min with the brake off. The lymphoid cells were recovered from the $40 \%$ / 70\% Percoll interphase and washed with PBS.

The mouse liver myeloid cell isolation protocol was based on the method published by Wu et al. [22] with minor modifications. Mice were deeply anesthetized prior to opening the abdomen to expose the portal vein and inferior vena cava. The liver was perfused with $50 \mathrm{~mL}$ of $\mathrm{Ca}^{2+} / \mathrm{Mg}^{2+}$-free Hank's balanced salt solution (HBSS), followed by perfusion of $40 \mathrm{~mL}$ of $0.05 \%$ collagenase (Sigma-Aldrich) solution in $\mathrm{Ca}^{2+} / \mathrm{Mg}^{2+-}$ containing HBSS through the portal vein at $37{ }^{\circ} \mathrm{C}$ with a $5 \mathrm{~mL} / \mathrm{min}$ flow rate. The collagenase-digested liver was isolated and dispersed in $50 \mathrm{~mL}$ of $\mathrm{Ca}^{2+} / \mathrm{Mg}^{2+-}$ containing HBSS supplemented with $3 \%$ FBS to release intrahepatic cells. The cell suspension was centrifuged at $50 \times \mathrm{g}$ twice to separate hepatocytes and crude hepatic NPCs. The hepatic NPCs in the supernatant were pelleted by centrifugation at $300 \times \mathrm{g}$.
The crude NPCs were labeled with a phycoerythrinconjugated anti-mouse CD45 antibody, and the CD45 leukocytes were positively selected with anti-phycoerythrin IMAG-magnetic microbeads (BD Bioscience) according to the manufacturer's suggestion. Both isolated lymphoid cells and isolated myeloid cells were resuspended in $0.1 \mathrm{~mL}$ of PBS containing 3\% FBS for further analysis. Total isolated cell counts were calculated with a hemocytometer under a microscope.

\section{Mouse peripheral blood mononuclear cell isolation and the complete blood count}

Mouse whole blood was collected in K2-EDTA tubes (BD Bioscience). Blood samples $(100 \mu \mathrm{l})$ were subjected to red blood cell lysis by adding $4 \mathrm{~mL}$ of ACK lysis buffer (Thermo Fisher Scientific) and incubated for $5 \mathrm{~min}$. After neutralization with $30 \mathrm{~mL}$ of PBS, mouse PBMCs were pelleted by centrifugation at $300 \times \mathrm{g}$ and resuspended in $0.1 \mathrm{~mL}$ of PBS containing 3\% FBS for further analysis. Complete blood count analysis was conducted 
(a)

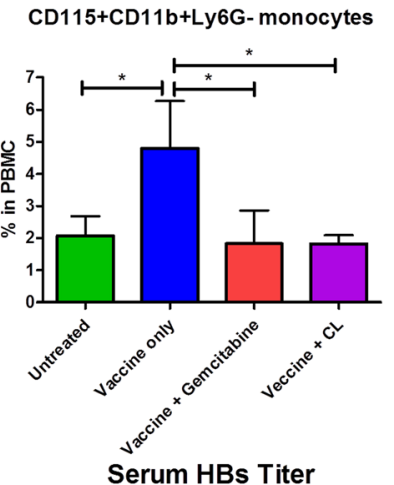

(c)

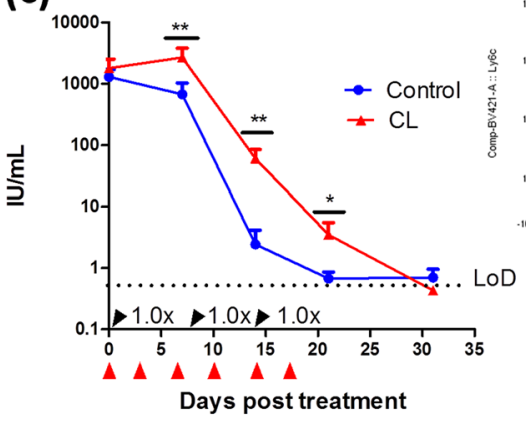

(d)

Serum HBs Titer

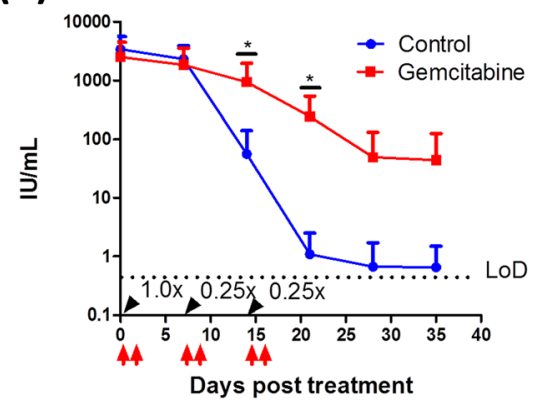

(b)

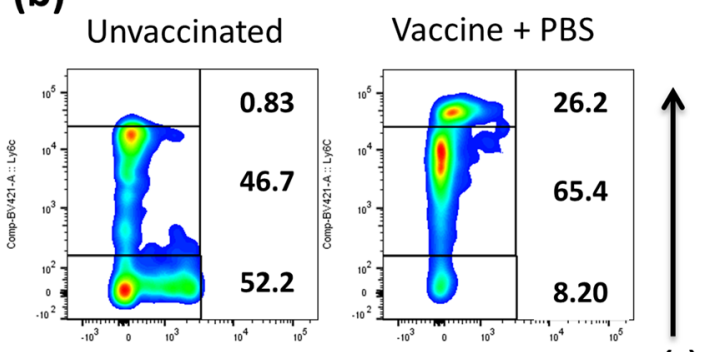

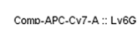

Vaccine $+\mathrm{CL}$

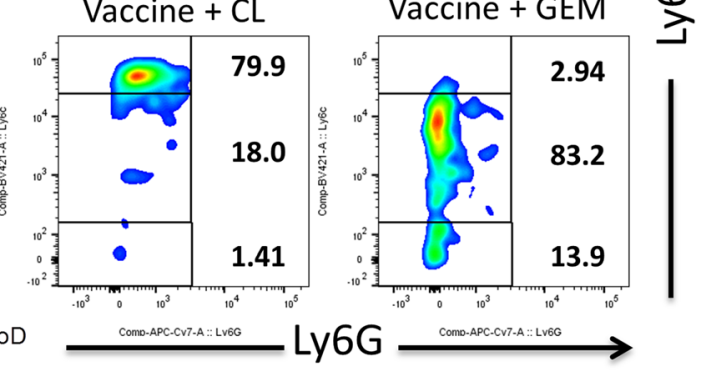

(e)

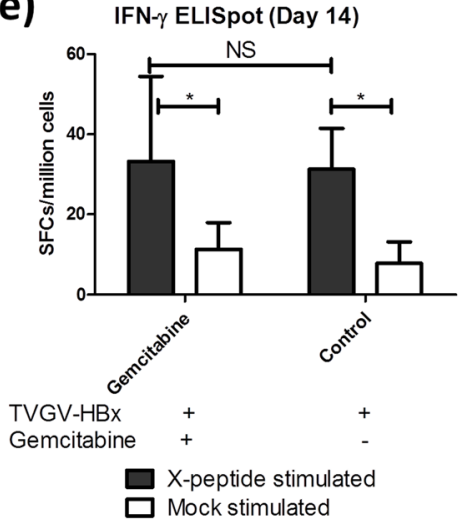

Fig. 5 CpG-ODN-induced monocyte mobilization regulates TVGV-HBX-mediated HBV clearance. a-b HBV carrier mice ( $N=3$ ) received TVGV-HBX on day 0 . Gemcitabine $(40 \mathrm{mg} / \mathrm{kg}$ ) was given by intraperitoneal injection on days 0 and 1. CLs (200 $\mu \mathrm{L})$ were given by intravenous injection on day 0. PBMCs were isolated on day 2. PBMCs were stained with fluorochrome-conjugated anti-CD11b, anti-CD115, anti-Ly6C and anti-Ly6G antibodies and then subjected to FACS analysis. a Frequency of CD11 $\mathrm{b}^{+} \mathrm{CD} 115^{+} \mathrm{Ly} 6 \mathrm{G}^{-}$monocytes among total PBMCs. b Representative FACS plots of $\mathrm{Ly}_{6 \mathrm{C}^{+}}$monocyte subsets (gated by CD11b $+\mathrm{CD} 115+\mathrm{Ly} 6 \mathrm{G}-$ ) before and after vaccination and drug administration. The cell frequencies of each subpopulation are shown on the plot. c-d HBV carrier mice $(\mathrm{N}=4 \sim 5)$ were administered TVGV-HBx vaccination (black arrow with the dosage indicated, $100 \mu \mathrm{g}$ of antigen plus $20 \mu \mathrm{g}$ of $\mathrm{CpG}-\mathrm{ODN}$ as 1.0x) and a monocyte-depleting drug (red arrow) at the indicated time points. Blood samples were collected at the indicated time points. c Serum HBs titer after TVGV-HBx vaccination and CL treatment. d Serum HBs titer after TVGV-HBx vaccination and gemcitabine treatment. e Splenocyte IFN- $\gamma$ ELISpot results (mice N=5) after TVGV-HBx vaccination and gemcitabine treatment. The vaccination and drug administration protocol were the same as in (d), and the splenocytes were harvested on day 14. Cells were stimulated with HBx-derived 15-mer overlapping peptides. Statistics: Student's t-test. ${ }^{*}, p<0.05 ;{ }^{*}, p<0.01$; NS, not significant; LoD, limit of detection; SFCs, spot-forming cells; GEM, gemcitabine

with the ProCyte Dx Hematology Analyzer (IDEXX, Westbrook, ME, USA) with $100 \mu \mathrm{L}$ of whole blood.

\section{Flow cytometry analysis}

Isolated liver leukocytes or PBMCs were blocked with $5 \mu \mathrm{g} / \mathrm{mL}$ anti-mouse CD16/CD32 antibodies (BD Bioscience) and stained with fluorochrome-conjugated antibodies for $30 \mathrm{~min}$ at $4{ }^{\circ} \mathrm{C}$ in the dark. The cells were washed twice with PBS containing 3\% FBS and fixed in
$0.5 \mathrm{~mL}$ of Fluorofix buffer (BioLegend) for $30 \mathrm{~min}$. The fixed cells were washed with PBS containing 3\% FBS once and then analyzed on a FACSFortessa instrument (BD Bioscience). The fluorochrome-conjugated antibodies used in this study included FITC-conjugated anti-CD3, FITCconjugated anti-CD11b, phycoerythrin-conjugated antiCD45, APC-conjugated anti-CD8, APC-conjugated antiCD115, APC/Cy7-conjugated anti-CD45, APC/Cy7-conjugated anti-Ly6G, BV605-conjugated anti-CD4, BV605- 
conjugated anti-Ly6G, BV421-conjugated anti-Ly6C, PerCP/Cy5.5-conjugated anti-CD19, PerCP/Cy5.5-conjugated anti-F4/80 (all purchased from BioLegend) and BV421-conjugated anti-CD11a (BD Bioscience). The compensation settings of the flow cytometer were determined with single-stained Ultracomp eBeads (Thermo Fisher Scientific). The frequency of each cell subpopulation obtained by flow cytometric analysis was further multiplied by the total isolated cell count to obtain the cell number for each subpopulation.

\section{Administration of monocyte-depleting drugs}

Clodronate liposomes (CLs) are a substance with selective toxicity to phagocytic mononuclear cells, including phagocytic monocytes and macrophages. CLs (Encapsula NanoSciences, Brentwood, TN, USA) or control liposomes were given at $200 \mu \mathrm{L}$ per mouse via intravenous tail vein injection. Administration was conducted twice per week for 3 weeks. Gemcitabine is a DNA synthesis inhibitor that has been reported to selectively deplete Ly6Chigh inflammatory monocytes (Ly6C high monocytes) [23]. Gemcitabine (Sigma-Aldrich) was dissolved in PBS, and a $40 \mathrm{mg} / \mathrm{kg}$ dose was given via intraperitoneal injection on days 0 and 1 after every vaccination dose.

\section{Statistical analyses}

All statistical analyses were performed using Prism 5 software (GraphPad, San Diego, CA, USA). All data are presented as the mean and standard deviation. The significance of differences between groups was assessed by Student's $t$-test. Symbols: * $p<0.05$; * $p<0.01$; *** $p<0.001$.

\section{Results}

\section{Potent immunogenicity of an $\mathrm{HBx}$-based therapeutic} vaccine in $\mathrm{CBA} / \mathrm{CaJ}$ mice

To investigate the potency of an HBx-based, CpG-ODNadjuvanted novel therapeutic vaccine formulation, namely, TVGV-HBx, in an animal model that mimics human HBV carriers, we utilized a previously established hydrodynamic injection (HDI) based model [20] that has been widely adopted for HBV-related vaccine studies [24, 25]. We chose a specific mouse strain, $\mathrm{CBA} / \mathrm{Ca}$, because it showed the highest HBV persistence rate and viral titer after HDI-based pAAV/HBV1.2 plasmid transfection among all tested mouse strains [26]. We first studied the persistence rate of 3 different genotypes (A, B and C) of the pAAV/HBV1.2 plasmid in CBA/CaJ mice. After a single HDI, HBs remained persistent in the mouse blood for more than 6 months without anti-HBs antibody production (Fig. 1a and Supplementary Figure 2). Because the genotype A plasmid resulted in the highest persistence rate, all subsequent experiments were performed using the genotype A plasmid unless otherwise indicated.
We next examined the immunogenicity of TVGV-HBx in naïve mice. Three weekly doses of TVGV-HBx, TVGV-E7 (an HPV-E7 control vaccine) or PBS were separately administered to naïve mice. As it is difficult to reliably assay the antibody responses to $\mathrm{HBx}$, we studied $\mathrm{HBx}$-specific $\mathrm{T}$ cell responses instead. Splenocytes from each group were subjected to an IFN- $\gamma$ ELISpot assay 7 days after the last immunization. The TVGV-HBximmunized group exhibited a significant increase in IFN- $\gamma$ secretion in response to $\mathrm{HBx}$-derived peptide stimulation but not in response to $\mathrm{HBc}$-derived peptide stimulation or mock stimulation (Fig. 1b). The TVGVE7-immunized and unimmunized mice did not exhibit significant $\mathrm{HBx}$-specific $\mathrm{T}$ cell responses. These data suggested that TVGV-HBx immunization induced sufficient $\mathrm{HBx}$-specific $\mathrm{T}$ cell immunity in naïve mice.

To study whether TVGV-HBx induces protection against HBV, mice received 3 weekly doses of TVGV$\mathrm{HBx}$ and CpG-ODN then followed by HDI pAAV/ HBV1.2 plasmid challenge 7 days after the last immunization. We examined the HBV titer by measuring serum HBs and HBV-DNA levels in vaccinated mice at the indicated time points (Fig. 1c and d). The serum HBs level of the TVGV-HBx-immunized mice was approximately 100 -fold lower than that of the mice immunized with only the adjuvant CpG-ODN at 28 days post HDI (Fig. 1c). Similar to the HBs level, the serum HBVDNA titer rapidly decreased to undetectable levels within 2 weeks after pAAV/HBV1.2 plasmid injection in the TVGV-HBx vaccinated group, while the level in the adjuvant group remained high (Fig. 1d). Compared with the CpG-ODN group, the TVGV-HBx-vaccinated group showed a significant reduction in the liver $\mathrm{HBc}$ protein level (Fig. 1e). The liver HBV-DNA level was also reduced by approximately 60-fold on average (Fig. 1f). This suggests that prophylactic administration of the TVGV-HBx vaccine induces a protective immune response against HBV that removes both HBV proteins and DNA templates from mouse liver challenged with pAAV/HBV1.2 plasmid.

\section{TVGV-HBx vaccination clears $\mathrm{HBs}$ and $\mathrm{HBV}$-DNA in HBV carrier mice}

After confirming the immunogenicity of the TVGV-HBx vaccine in naïve mice, we examined whether the TVGV$\mathrm{HBx}$ vaccine could eradicate HBV (HBV genotype C; Fig. 2a-e) in carrier mice. Different vaccine formulations, including TVGV-HBx, TVGV-E7, CpG-ODN and PBS alone, were each administered to HBV carrier mice weekly for 3 weeks. The therapeutic efficacies of the vaccine formulations were evaluated by determining the clearance rates of serum HBs and HBV-DNA. As a result, compared with the PBS-, CpG-ODN-, and TVGVE7-vaccinated groups, the TVGV-HBx-treated group 
displayed rapid and significant reductions in serum HBs and HBV-DNA levels (Fig. 2a and b), indicating that therapeutic TVGV-HBx vaccination was able to dramatically decrease serum viral titers in HBV carrier mice. However, after HBs was cleared from the serum, we did not find protective anti-HBs antibody production in the serum (Fig. 2c). This result suggested that immunization with the $\mathrm{HBx}$ vaccine alone did not restore anti-HBs antibody production and that the removal of $\mathrm{HBs}$ from the serum was not due to a neutralizing antibody. At the endpoint of the experiment, all TVGV-HBx-vaccinated HBV carrier mice exhibited undetectable liver $\mathrm{HBc}$ and HBV-DNA levels, demonstrating complete HBV clearance from the liver (Fig. $2 \mathrm{~d}$ and e). These findings suggested that TVGV-HBx immunization was able to eliminate preexisting $\mathrm{HBV}$-expressing hepatocytes in HBV carrier mice. Furthermore, compared with the PBS group, both the CpG-ODN-treated groups (TVGV-E7 with the adjuvant CpG-ODN and CpG-ODN alone) showed a 2- to 4-fold decrease in the serum HBs level (Fig. 2a), and a couple of mice $(2 / 12,17 \%)$ achieved liver HBV-DNA clearance (Fig. 2e). These results indicate that the adjuvant $\mathrm{CpG}-\mathrm{ODN}$ may trigger innate immune responses that partially contribute to $\mathrm{HBV}$ clearance. Similar TVGV-HBx therapeutic efficacy were obtained with HBV carrier mice injected with other HBV genotypes $(\mathrm{A}, \mathrm{B}$, and $\mathrm{D})$, indicating that the TVGV-HBxinduced antiviral activity was not limited to a specific HBV genotype (Supplementary Figure 3a-c).

\section{TVGV-HBx vaccination induces an $\mathrm{HBX}$-specific $\mathrm{T}$ cell response and posttherapy protective effects in the context of HBV viremia}

High antigen loads have been reported to inhibit effector $\mathrm{T}$ cell function, which is a key factor in viral clearance. Splenocytes were collected from HBV carrier mice after immunization with 3 weekly doses of TVGV-HBx to assess the efficacy of TVGV-HBx vaccination in inducing systemic $\mathrm{T}$ cell-mediated immunity in the context of HBV viremia. $\mathrm{HBx}$-specific $\mathrm{T}$ cell ELISpot assay results revealed that TVGV-HBx-immunized carriers exhibited a specific response to an $\mathrm{HBx}$-derived peptide, but those in the mock-stimulated group did not (Fig. 3a). To determine whether the TVGV-HBx-induced T cell response involves $\mathrm{CD}^{+}$or $\mathrm{CD}^{+}$subpopulations, in the same experiment, we predepleted $\mathrm{CD} 4^{+}$or $\mathrm{CD} 8^{+} \mathrm{T}$ cells during splenocyte preparation and compared the resultant ELISpot results with those for nondepleted splenocytes. The results showed that both $\mathrm{CD} 4^{+}$cell- and $\mathrm{CD} 8^{+}$cell-depleted splenocytes demonstrated a significant decrease in the TVGV$\mathrm{HBx}$-induced $\mathrm{T}$ cell response, with the drop in the $\mathrm{CD} 4^{+}$ cell-depleted group being greater than that in the $\mathrm{CD} 8^{+}$ cell-depleted group (Fig. 3b). To confirm whether vaccineinduced cytotoxic $\mathrm{T}$ cells infiltrate the liver, we analyzed the hepatic $\mathrm{CD}^{+} \mathrm{T}$ cell quantity at day 10 when the serum HBs titer was descending (Fig. 2a and Supplementary Figure 3a-c). We found that compared to that in the CpG-ODN alone group, the $\mathrm{CD} 8^{+} \mathrm{T}$ cell number in the liver in the TVGV-HBx-immunized group was significantly increased (Fig. 3c). In addition, we also found that most of the liver $\mathrm{CD}^{+} \mathrm{T}$ cells in the increased population were $\mathrm{CD} 11 \mathrm{a}^{+} \mathrm{CD}^{+}$cells (Fig. 3d), which have been reported to be antigen-experienced cytotoxic $\mathrm{T}$ cells that are important for hepatic HBV clearance [24, 27]. These findings signify that TVGV-HBx immunization is able to induce systemic $\mathrm{HBx}$-specific $\mathrm{CD} 4^{+}$and $\mathrm{CD} 8^{+} \mathrm{T}$ lymphocytes in $\mathrm{HBV}$ carrier mice and that vaccine-induced $\mathrm{CD} 8^{+}$ T lymphocytes will infiltrate the liver to eliminate HBV.

After confirming that the TVGV-HBx vaccine could clear $\mathrm{HBV}$ in the liver, we further investigated whether the TVGV-HBx vaccine is able to provide a long-lasting protective effect against a second HBV exposure after the initial cure. We immunized HBV carrier mice with 3 weekly doses of TVGV-HBx or the adjuvant alone. At day 32 after the first HBV clearance, we re-challenged all animals with the same pAAV/HBV1.2 plasmid by HDI and measured the serum HBs titer weekly. The results showed that without an additional booster immunization, the serum HBs level following the second HBV exposure was significantly reduced by approximately 25 -fold in the TVGV-HBx-immunized mice compared with the adjuvant-alone group (Fig. 3e). Western blot analysis of liver tissue confirmed that TVGV-HBx immunization led to the clearance of most $\mathrm{HBC}$ after the second HBV exposure (Fig. 3f). These results implied that TVGV-HBx vaccination provided a protective effect after vaccination to accelerate the clearance of $\mathrm{HBV}$ after the second exposure. However, the mice could not immediately eliminate serum HBs after the second challenge, suggesting weaker intrahepatic immunity during the second HBV exposure than during the first.

\section{$\mathrm{HBC}$ and $\mathrm{HBx}$, as immunogens, induce distinct types of immunity against $\mathrm{HBV}$}

To explore the impact of immunogen selection on the efficacy of therapeutic vaccination in HBV carrier mice, we compared the HBV clearance potency of $\mathrm{HBc}$, a relatively abundant and highly immunogenic structural protein of $\mathrm{HBV}$, with that of $\mathrm{HBx}$, with both proteins used as immunogens. CpG-ODN-adjuvanted recombinant $\mathrm{HBx}$ or $\mathrm{HBc}$ were administered to $\mathrm{HBV}$ carrier mice at a previously titrated minimal effective dosage of TVGVHBx (Supplementary Figure 4). As expected, the HBximmunized mice had completely eliminated serum HBs at day 31, whereas $\mathrm{HBc}$ immunization exhibited a minimal impact on serum $\mathrm{HBs}$ clearance, indicating that $\mathrm{HBC}$ is a less effective immunogen than HBx in mice (Fig. 4a). In addition, we also evaluated the status of humoral immunity after immunization with the different 
antigens by evaluating anti-HBs and anti-HBc antibody production at the endpoint of the experiment. As shown, neither $\mathrm{HBc}$ - nor $\mathrm{HBx}$-immunized mice exhibited antiHBs antibody production (Fig. 4b). All mice were positive for anti-HBc antibodies in the serum, indicating that the hepatocytes expressing $\mathrm{HBc}$ in this model could induce baseline antibody production. Among the $\mathrm{HBC}$ immunized mice, the anti-HBc antibody level was higher than that in the $\mathrm{HBx}$-immunized mice and exceeded the detection limit even with a 10-fold dilution (Fig. 4c). This result suggested that $\mathrm{HBc}$ immunization potently bolstered anti-HBc antibody production in mice but did not result in HBV clearance. We also evaluated the splenic $\mathrm{T}$ cell response against corresponding peptides derived from each antigen, which showed that only $\mathrm{HBx}$ immunization, not $\mathrm{HBC}$ immunization, resulted in strong induction of antigen-specific IFN- $\gamma$-secreting $\mathrm{T}$ cells (Fig. 4d). These results imply that the HBx-based vaccine induces better cellular immunity than the $\mathrm{HBc}$-based vaccine. Since antigen-specific $T$ cell response induction is critical to viral clearance, this result was in concordance with the serum HBs clearance rate results indicating that $\mathrm{HBx}$ had better immunogenicity, resulting in elimination of persistent HBV, than HBc (Fig. 4a).

\section{TVGV-HBx vaccination promotes HBV clearance by mobilizing monocytes}

To explore possible innate immune modulators that contribute to vaccine-mediated HBV clearance, we monitored the blood leukocyte count changes in TVGV-HBx-, TVGV-E7-, CpG-ODN- and PBS-immunized mice twice a week. Among the counts of all blood leukocyte types, only the monocyte count showed TVGV-HBx-specific changes. All CpG-ODN-containing groups demonstrated elevated monocyte counts at day 3 postvaccination. Interestingly, only the TVGV-HBx-immunized mice showed delayed deflation at day 7 postimmunization (Supplementary Figure 5). Based on this observation, we speculated that vaccine-mobilized monocytes are associated with TVGV-HBx-induced HBV clearance.

Next, we investigated whether removing monocytes impacts the efficacy of TVGV-HBx vaccination. We tested 2 monocyte-depleting drugs, CLs and gemcitabine, in mice and checked their blood monocyte frequency after TVGV-HBx stimulation and drug treatment. We observed that TVGV-HBx immunization strongly mobilized $\mathrm{CD}_{11} \mathrm{~b}^{+} \mathrm{CD} 115^{+} \mathrm{Ly}_{6 \mathrm{G}}{ }^{-}$monocytes into the blood, with especially Ly6C ${ }^{\text {high }}$ monocytes showing a dramatic expansion (Fig. 5a and b). After drug administration, compared with the vaccine-only group, the $\mathrm{CL}$ and gemcitabine groups each showed an approximately $50 \%$ reduction in the $\mathrm{CD} 11 \mathrm{~b}^{+} \mathrm{CD} 115^{+} \mathrm{Ly} 6 \mathrm{G}^{-}$blood monocyte frequency (Fig. 5a). Interestingly, CLs and gemcitabine depleted different monocyte subpopulations according to surface
Ly6C expression. CLs mainly depleted Ly6C-intermediate and Ly6C-low monocyte-derived macrophages $\left(\right.$ Ly6 $\mathrm{C}^{\text {int }}$ and Ly6 $\mathrm{C}^{\text {low }} \mathrm{MoMs}$, respectively), probably due to their selective cytotoxicity to phagocytic cells (Fig. 5b). In contrast, gemcitabine depleted almost all Ly6C $\mathrm{C}^{\text {high }}$ monocytes (Fig. 5b). Neither CLs nor gemcitabine depleted

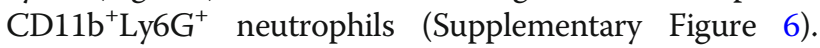
After checking the depletion efficiencies of both drugs, we administered TVGV-HBx immunization to mice pretreated with CLs or gemcitabine and tested serum HBs clearance. In the CL depletion experiment, we treated animals with CLs twice a week until day 17 to maintain the depletion of phagocytic macrophages during the therapy course and compared this group against the control liposome-treated group. The CL depletion group showed an increased serum HBs level from day 7 to 21 but eventually displayed a modest difference in the HBs clearance profile (Fig. 5c). This result suggests that without phagocytic Ly6C $C^{\text {int }}$ and Ly6C $C^{\text {low }}$ MoMs, the presence of Ly6C high monocytes alone is sufficient to support vaccine-induced HBV clearance. To further investigate the significance of Ly6 $\mathrm{C}^{\text {high }}$ monocytes in vaccine-mediated HBV clearance, we treated animals with gemcitabine at days 0 and 1 after every vaccination dose to inhibit vaccine-induced Ly $6 C^{\text {high }}$ monocyte mobilization and minimize the suppressive effect on proliferating T cells. Mice treated with gemcitabine showed significantly delayed HBs clearance from day 14 to 21 , which resulted in a 60-fold higher serum HBs level in the treated group than in the control group at the endpoint of the experiment (Fig. 5d). None of the gemcitabine-treated mice achieved complete HBV clearance. Since gemcitabine is a DNA synthesis inhibitor that could possibly inhibit $\mathrm{T}$ cell proliferation in the secondary lymphoid organs, we conducted splenic IFN- $\gamma$ ELISpot experiments on days 14 and 21 with the same administration protocol to determine whether systemic $\mathrm{T}$ cell immunity is affected by gemcitabine treatment. As indicated by the results, gemcitabine-treated mice did not exhibit deficiencies in systemic $\mathrm{HBx}$-specific $\mathrm{T}$ cell immunity, suggesting that the inhibitory effect of gemcitabine treatment cannot be attributed to systemic $\mathrm{T}$ cell suppression (Fig. 5e and Supplementary Figure 7).

\section{$\mathrm{CL}$ and gemcitabine treatments alter the liver immune environment after vaccination and impacts HBs clearance} Based on our previous observation that gemcitabine suppresses HBV clearance without affecting systemic immunity, we speculated that gemcitabine exerts an inhibitory effect by interfering with liver-resident innate immunity. We then investigated whether CpG-ODNmobilized monocytes infiltrate the liver and whether their infiltration is affected by CL or gemcitabine treatment. On day 2 postvaccination, we isolated total intrahepatic leukocytes from TVGV-HBx-immunized carrier 
mice and then compared their monocyte frequency and absolute cell counts to that of unimmunized mice (Supplementary Figure 8). First, we noted a prominent liver monocyte infiltration after vaccination (Fig. 6a). Most of these cells were found to be $\mathrm{Ly} 6 \mathrm{C}^{\text {high }}$ monocytes and Ly6C ${ }^{\text {int }}$ MoMs, whereas the numbers of Ly6C ${ }^{\text {low }}$ cells and Kupffer cells (KCs) did not increase (Fig. 6b). After drug treatment to TVGV-HBx vaccinated mice, both the $\mathrm{CL}$ and gemcitabine groups showed a reduced total monocyte number in the liver (Fig. 6a). CLs mainly depleted phagocytic macrophages, including $L y 6 C^{\text {int }}$ and Ly6 $\mathrm{C}^{\text {low }}$ MoMs and KCs, and had no impact on Ly6C $\mathrm{C}^{\text {high }}$ monocytes (Fig. 6b). On the other hand, gemcitabine had the strongest influence on liver Ly6 $\mathrm{C}^{\text {high }}$ monocytes, and the reductions in $\mathrm{KC}$ and $\mathrm{Ly} 6 \mathrm{C}^{\text {int }}$ and $\mathrm{Ly} 6 \mathrm{C}^{\text {low }}$ MoM counts were similar to those seen with CL treatment (Fig. 6b). Overall, CLs, in comparison to gemcitabine, did not deplete Ly6C $\mathrm{C}^{\text {high }}$ monocytes (Fig. 6c). The long-term inhibitory effect on HBV clearance occurred only when hepatic Ly6C $C^{\text {high }}$ monocytes were depleted (Fig. 5c and d). Collectively, our results implied that Ly6 $\mathrm{C}^{\text {int }}$ and Ly6C ${ }^{\text {low }}$ MoMs or KCs might be transiently involved in the early stage but were not the deciding factor in vaccine-mediated HBV clearance. In contrast, liver-infiltrating Ly6C $\mathrm{C}^{\text {high }}$ monocytes might play more important roles in TVGV-HBx-induced immune clearance.

\section{Discussion}

Our study shows that our CpG-ODN-adjuvanted HBx-based vaccine is able to induce an effective $\mathrm{HBx}$-specific $\mathrm{T}$ cell response, including both $\mathrm{CD}^{+}$and $\mathrm{CD}^{+}$subpopulations, to remove persistent $\mathrm{HBV}$ genome templates from the $\mathrm{HBV}$ carrier mouse liver. As described previously, we chose the low-expressed viral $\mathrm{HBx}$ as the antigen because it may have advantages in avoiding excessive antigen-induced $\mathrm{T}$ cell exhaustion. However, using a low-expressed intracellular antigen has other potential disadvantages, such as the lowexpressed antigen potentially reducing the level of the class I MHC-peptide complex on hepatocytes and decreasing the ability of $\mathrm{CD}^{+} \mathrm{T}$ cells to recognize target cells. The low $\mathrm{HBx}$ transcript expression levels found in our animal models in this study are similar to those in HBV-infected primary human hepatocytes $[14,28]$. Under such conditions, TVGV$\mathrm{HBx}$-induced adaptive immunity was still able to eliminate HBV-expressing hepatocytes, supporting the feasibility of using $\mathrm{HBx}$ as a therapeutic target in $\mathrm{CHB}$. On the other hand, the protein expression of $\mathrm{HBx}$ is highly associated with $\mathrm{HBC}$ in HBV-infected hepatocytes [29]. Since HBc is necessary for producing new infectious viral particles, elimination of HBx-expressing hepatocytes also removes the source of infectious viral particles, which makes $\mathrm{HBx}$ a reasonable therapeutic target. Moreover, after TVGV-HBx treatment, we found that residual protective immunity could last for at least 30 days to reduce the HBV titer after a second HBV exposure, suggesting the existence of immune memory or long-lived effector $\mathrm{T}$ cells. However, this immune response was weaker than that observed directly after therapeutic immunization, probably owing to the lack of CpG-ODN-mediated local immune modulation during hepatic immune clearance. As reported in another study, prime-and-boost vaccination alone is not sufficient to clear HBV unless the vaccine is boosted with CpG-ODN [30].

We found that antigen selection strongly affected the type of adaptive immunity induced. When supplemented with CpG-ODN, HBx immunization induced a large amount of antigen-specific $\mathrm{T}$ cells and cleared HBV in carrier mice. In contrast, CpG-ODN-adjuvanted HBc did not show significant induction of antigen-specific $\mathrm{T}$ cells but instead induced a high level of anti-HBc antibody production. This result is in concordance with a previous vaccine study conducted in HBV transgenic mice [31]. This phenomenon might result from the preferential uptake and presentation of naked $\mathrm{HBc}$ by $\mathrm{B}$ cells instead of dendritic cells or macrophages [32]. Another possibility is that mouse $\mathrm{HBc}$-specific $\mathrm{T}$ cells are already exhausted prior to immunization.

We were unable to directly detect anti-HBx antibodies due to the lack of a reliable assay, but recognition of an intracellular protein by antibodies is not expected to have important roles in HBV immune clearance. No signs of protective anti-HBs antibody recovery were observed after the clearance of serum HBs. This result indicates that treatment with the $\mathrm{HBx}$ vaccine alone is not sufficient for the restoration of humoral immunity against $\mathrm{HBs}$, despite the recovery of the $\mathrm{HBx}$-specific $\mathrm{T}$ cell response. The restoration of anti-HBs antibody production may require additional HBs immunization. The removal of the HBs burden from the circulation may contribute to the recovery of anti-HBs antibody production, but it still requires further investigation.

Although the first priming of antigen-specific $\mathrm{T}$ cells in mice treated with peripheral vaccination usually occurs in the secondary lymphoid tissues, including the spleen or local draining lymph nodes, the tolerogenic liver environment hampers $\mathrm{T}$ cell-mediated immune clearance in both antigen-specific and nonspecific manners $[11,16,17]$. Hepatic myeloid cells, including GR1 ${ }^{+}$ neutrophils, monocytes, and KCs, have been suggested to promote hepatic HBV antigen clearance [18, 33, 34]. However, myeloid cells are highly heterogeneous [35], and the lack of depletion reagents specific for individual subpopulations increases the difficulty of performing functional analyses. We show that TVGV-HBx vaccination induces robust systemic mobilization and liver infiltration of monocytes, including Ly6 $\mathrm{C}^{\text {high }}$ monocytes and Ly6C ${ }^{\text {int }}$ MoMs, both of which were previously 


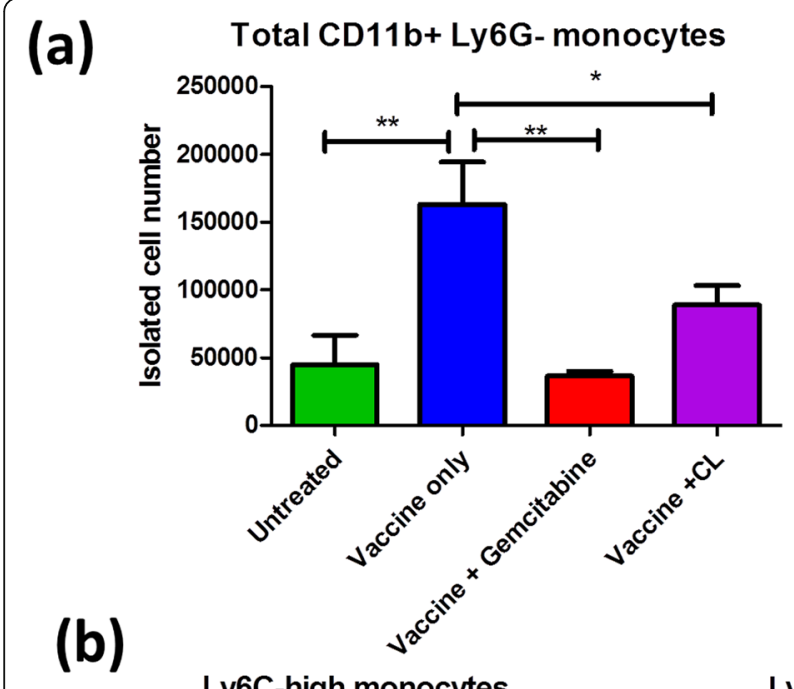

Ly6C-high monocytes
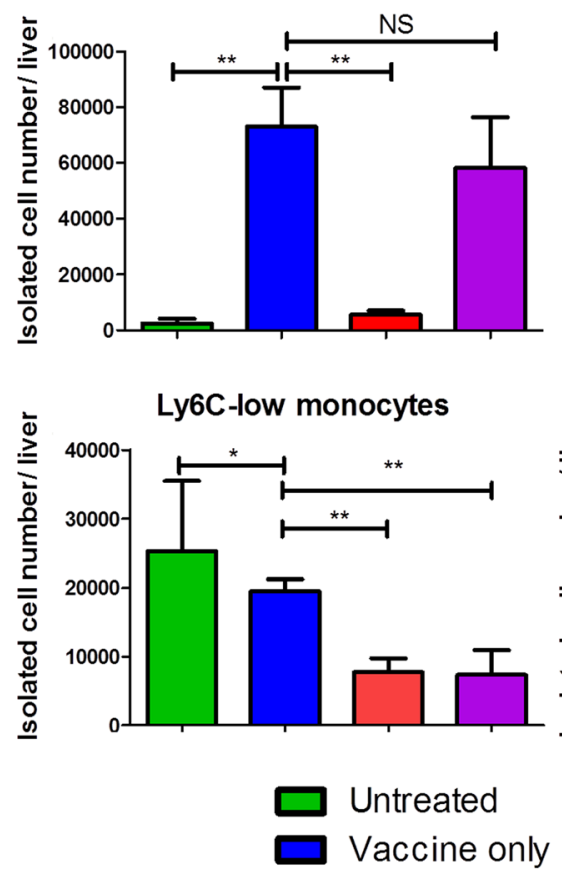

Ly6C-int monocytes

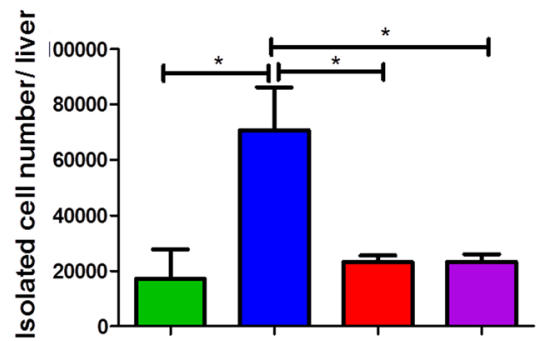

KCs

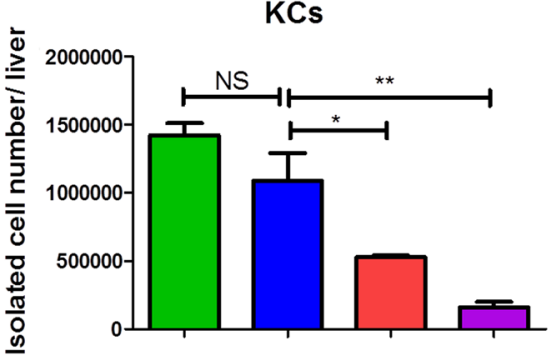

\section{Depleted by $\mathrm{CL}$}

Depleted by Gemcitabine

Fig. 6 Liver monocyte subpopulation changes after TVGV-HBx vaccination and monocyte-depleting drug treatment. a-b HBV carrier mice ( $N=4$ ) received TVGV-HBx on day 0 . Gemcitabine $(40 \mathrm{mg} / \mathrm{kg}$ ) was given by intraperitoneal injection on days 0 and 1 . CLs ( $200 \mu \mathrm{L}$ ) were given by intravenous injection on day 0. Total intrahepatic leukocytes were collected on day 2 and subjected to flow cytometric analysis. The isolated cell count of each cell subpopulation was calculated by multiplying the actual isolated CD45 leukocyte count per liver by the subpopulation frequency among isolated cells. a Total isolated cell

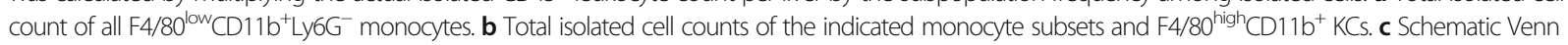
diagram of liver myeloid cell subpopulations depleted by CL or gemcitabine treatment. Statistics: Student's t-test. *, p $<0.05$; **, p < 0.01; NS, not significant

reported to be participants in intrahepatic myeloid cell aggregates for $\mathrm{T}$ cell population expansion [18]. Through CL- and gemcitabine-mediated cell depletion, we discovered distinctive roles for intrahepatic monocyte subpopulations in resolving hepatic HBV exposure. Phagocytic macrophages, including Ly6 $\mathrm{C}^{\text {int }} \mathrm{MHCII}^{+} \mathrm{MoMs}$, are the major antigen-presenting cells that support intrahepatic $\mathrm{T}$ cell proliferation [18]. However, our model suggests that the removal of these cells by CLs is not sufficient to suppress vaccine-induced HBV clearance. In contrast, a sustained suppressive effect on HBV clearance occurred only when Ly6C $C^{\text {high }}$ monocytes were depleted. Ly6C $C^{\text {high }}$ monocytes may also support $\mathrm{T}$ cell proliferation in the liver. In addition, they are good producers of multiple immunomodulators, such as IL-12, TNF- $\alpha$, MCP-1, CXCL10, and CCL5, all of which may modulate the tolerogenic hepatic microenvironment toward immune clearance [36, 37]. Among these cytokines, IL-12 also 
augments NK cell secretion of IFN- $\gamma$ and promotes NK cell cytotoxicity [38], which may explain why a small number of CpG-ODN-receiving carrier mice also showed HBV load reduction or clearance. Among liverinfiltrating myeloid cells, Ly6C ${ }^{\text {high }}$ monocytes might have pivotal roles in preconditioning the liver immune environment toward immune clearance and supporting subsequent infiltrating antigen-specific $\mathrm{T}$ cells in exerting their cytotoxic function to eliminate HBV (Supplementary Figure 9). Our results highlight the significance of Ly6 $\mathrm{C}^{\text {high }}$ monocytes in regulating hepatic immunity during $\mathrm{CpG}-\mathrm{ODN}$-adjuvanted vaccination.

As has been shown in many other preclinical attempts with therapeutic $\mathrm{HBV}$ vaccines, including those containing $\mathrm{HBs}$ and $\mathrm{HBc}$, vaccine-receiving animals usually show excellent efficacy in reducing HBs and HBV-DNA titers, even in models that are reportedly "immune tolerant" toward HBV [18, 24, 30, 39]. Unfortunately, to our knowledge, no therapeutic vaccine has convincingly demonstrated clinical benefits in CHB patients. All current HBV immunologyrelated animal models, including HDI-based and adeno- or adeno-associated virus-transduced models, have limitations in imitating the host immune responses observed in $\mathrm{CHB}$ patients. CHB patients usually carry HBV and develop $\mathrm{T}$ cell exhaustion over multiple years or even decades, but in animal models, $\mathrm{T}$ cell exhaustion develops within approximately 4-6 weeks. Although these animal models show features of $\mathrm{T}$ cell exhaustion, including the expression of inhibitory receptors and reduced cytokine secretion in certain HBV-specific T cell clones [40, 41], it is still questionable whether their $\mathrm{T}$ cell exhaustion degree is comparable to that of $\mathrm{CHB}$ patients. Additionally, since rodents are not natural hosts of $\mathrm{HBV}$, the establishment of a CHB model in immunocompetent mice usually uses alternative transduction methods to substitute for natural infection; therefore, the transduced HBV genome does not evolve or generate variants that escape host immune responses. HBV clearance may be easier when viral proteins have less variation in a mouse model. Although our study provided evidence that the HBx-based vaccine can eliminate HBV-bearing hepatocytes in a mouse model, translation into clinical use still requires further investigation.

\section{Conclusions}

Our study demonstrates that the HBx-based vaccine successfully eliminates persistent $\mathrm{HBV}$ in an animal model and has the potential to be developed into a therapeutic vaccine against $\mathrm{CHB}$. The adjuvant CpGODN improves HBx-specific $\mathrm{T}$ cell functions by mobilizing Ly6 $\mathrm{C}^{\text {high }}$ monocytes to the liver and shifting the hepatic microenvironment toward one favoring immune clearance. The induction of optimal liver $\mathrm{Ly} 6 \mathrm{C}^{\text {high }}$ monocyte accumulation and the consequent modulatory effect on the hepatic immune environment are key to subverting the tolerogenic liver environment and facilitating $\mathrm{T}$ cell-mediated viral clearance. The appropriate immunogen design in combination with optimal hepatic innate immunity modulation might be important considerations for developing next-generation therapeutic vaccines to treat $\mathrm{CHB}$.

\section{Supplementary information}

Supplementary information accompanies this paper at https://doi.org/10. 1186/s12929-020-00662-x.

Additional file 1: Figure S1. Structures of RAP1-HBx, RAP1-E7 and pEt32a-HBx; Figure S2. HBV carrier mice do not produce protective antiHBs antibodies; Figure S3. HBx vaccine immunization removes serum HBs in mice carrying different HBV genotypes; Figure S4. TVGV-HBx exhibits antiviral activity in a dose-dependent manner; Figure S5. Quantification of CpG-ODN-induced monocyte changes in the blood; Figure S6. The effect of gemcitabine or clodronate liposome treatment on the blood neutrophil frequency; Figure S7. Gemcitabine treatment does not inhibit systemic T cell immunity; Figure S8. Representative flow cytometry plots of liver myeloid cell subpopulations after TVGV-HBx vaccination and monocyte depletion; and Figure S9. Schematic diagram of monocyte preconditioning of the liver immune environment and its impact on $\mathrm{HBx}$ therapeutic vaccine efficacy.

\section{Abbreviations}

HBV: Hepatitis B virus; CHB: Chronic hepatitis B; HBx: HBV X protein; HBs: HBV surface antigen; IFN: Interferon; HBC: HBV core antigen; PBMC: Peripheral blood mononuclear cell; NPC: Nonparenchymal cell; HDI: Hydrodynamic injection; PBS: Phosphate-buffered saline; HPV-E7: Human papillomavirus E7 protein; PE-A: Pseudomonas Exotoxin A; CpG-ODN: CpG oligodeoxynucleotides; rHBc: Recombinant HBV core antigen; rHBX: Recombinant HBV X protein; Q-PCR: Quantitative polymerase chain reaction; ELISpot: Enzyme-linked immunospot; HBSS: Hank's balanced salt solution; FBS: Fetal bovine serum; CL: Clodronate liposome; Ly6Chigh monocyte: Ly6C-high inflammatory monocyte; MoM: Monocyte-derived macrophage; KC: Kupffer cell

\section{Acknowledgements}

We thank Dr. Li-Rung Huang from the Taiwan National Health Research Institutes for providing professional opinions to help us refine this manuscript. We would like to acknowledge the services provided by the Flow Cytometric Analyzing and Sorting Core of the First Core Laboratory and Animal Center at the National Taiwan University College of Medicine. We also thank Dr. Xia Ning Shao and Dr. Yuan Quan from Xiamen University for providing experimental materials.

\section{Authors' contributions}

JH. H, WH. L and PJ. C designed the experiments. JH. H, WH. L and CR. W executed the experiments, and JH. H acquired the data. JH. H, YY. L, LL. W, DS. C and PJ. C were involved in the analysis and interpretation of the data. $J \mathrm{H}$. $\mathrm{H}$ and PJ. C wrote the manuscript. The authors read and approved the final manuscript.

\section{Funding}

This study was supported by the following institutions: the Ministry of Science and Technology, Taiwan (grant numbers: 105-2321-B-002-036; 1062321-B-002-011; 107-2321-B-002-002; and 108-2321-B-002-028); the National Taiwan University College of Medicine, Taipei, Taiwan; and TheVax Genetics Vaccine Company Limited, Taipei, Taiwan. TheVax Genetics Vaccine Company was partially involved in the study design but had no role in data collection, analysis, or interpretation or in manuscript writing. The other funders had no role in the study design; data collection, analysis, or interpretation; or manuscript writing.

\section{Availability of data and materials}

All data generated or analyzed during this study are included in this published article and the supplementary information files. 


\section{Ethics approval and consent to participate}

All animal experiment protocols were approved by the Institutional Animal Care and Use Committee (IACUC) at the National Taiwan University College of Medicine.

\section{Consent for publication}

Not applicable.

\section{Competing interests}

JH Horng received a scholarship from TheVax Genetics Vaccine Company WS Lin is a former employee of TheVax Genetics Vaccine Company. PJ Chen received research funding from TheVax Genetics Vaccine Company. The funding was limited to reimbursement for the necessary expenses for this research work. The other authors have no competing interests to report.

\section{Author details}

${ }^{1}$ Graduate Institute of Microbiology, National Taiwan University College of Medicine, No. 1 Jen Ai Road Section 1, Taipei, Taiwan (R.O.C.). ${ }^{2}$ TheVax Genetics Vaccine Company Limited, 5F, No. 25, Jen Ai Road Section 4, Taipei, Taiwan (R.O.C.). ${ }^{3}$ Graduate Institute of Clinical Medicine, National Taiwan University College of Medicine, No. 1, Jen Ai Road Section 1, Taipei, Taiwan (R.O.C.). ${ }^{4}$ Department \& Institute of Physiology, National Yang-Ming University, No. 155, Section 2, Linong Street, Taipei, Taiwan (R.O.C.). ${ }^{5}$ Division of Gastroenterology, Department of Internal Medicine, National Taiwan University Hospital, No. 1, Changde Street, Taipei, Taiwan (R.O.C.). ${ }^{6}$ Hepatitis Research Center, National Taiwan University Hospital, No. 1, Changde Street Taipei, Taiwan (R.O.C.)

\section{Received: 19 March 2020 Accepted: 18 May 2020}

Published online: 28 May 2020

\section{References}

1. Boni C, Fisicaro P, Valdatta C, Amadei B, Di Vincenzo P, Giuberti T, et al. Characterization of hepatitis B virus (HBV)-specific T-cell dysfunction in chronic HBV infection. J Virol. 2007;81:4215-25.

2. Bengsch B, Martin B, Thimme R. Restoration of HBV-specific CD8+ T cell function by PD-1 blockade in inactive carrier patients is linked to $T$ cell differentiation. J Hepatol. 2014;61:1212-9.

3. Schuch A, Salimi Alizei E, Heim K, Wieland D, Kiraithe MM, Kemming J, et al. Phenotypic and functional differences of HBV core-specific versus HBV polymerase-specific CD8+ T cells in chronically HBV-infected patients with low viral load. Gut. 2019;68:905-15.

4. Burton AR, Pallett L, McCoy LE, Suveizdyte $K$, Amin OE, Swadling L, et al. Circulating and intrahepatic antiviral $B$ cells are defective in hepatitis B. J Clin Invest. 2018;128:4588-603.

5. Gehring AJ, Protzer U. Targeting innate and adaptive immune responses to cure chronic HBV infection. Gastroenterology. 2019;156:325-37.

6. Maini MK, Pallett $L$ J. Defective T-cell immunity in hepatitis B virus infection: why therapeutic vaccination needs a helping hand. Lancet Gastroenterol Hepatol. 2018;3:192-202.

7. Boni C, Janssen HLA, Rossi M, Yoon SK, Vecchi A, Barili V, et al. Combined GS-4774 and tenofovir therapy can improve HBV-specific T-cell responses in patients with chronic hepatitis. Gastroenterology. 2019;157:227-41 e7.

8. Ma Z, Zhang E, Gao S, Xiong Y, Lu M. Toward a functional cure for hepatitis $B$ : the rationale and challenges for therapeutic targeting of the $B$ cell immune response. Front Immunol. 2019;10:2308.

9. Mueller SN, Ahmed R. High antigen levels are the cause of T cell exhaustion during chronic viral infection. Proc Natl Acad Sci U S A. 2009;106:8623-8.

10. Utzschneider DT, Alfei F, Roelli P, Barras D, Chennupati V, Darbre S, et al. High antigen levels induce an exhausted phenotype in a chronic infection without impairing T cell expansion and survival. J Exp Med. 2016;213:1819-34.

11. Tay SS, Wong YC, MCDonald DM, Wood NA, Roediger B, Sierro F, et al. Antigen expression level threshold tunes the fate of CD8 T cells during primary hepatic immune responses. Proc Natl Acad Sci U S A. 2014;111:E2540-9.

12. Dembek $\mathrm{C}$, Protzer $\mathrm{U}$, Roggendorf M. Overcoming immune tolerance in chronic hepatitis B by therapeutic vaccination. Curr Opin Virol. 2018;30:58-67.

13. Bouchard MJ, Schneider RJ. The enigmatic $X$ gene of hepatitis $B$ virus. J Virol. 2004;78:12725-34.

14. Niu C, Livingston CM, Li L, Beran RK, Daffis S, Ramakrishnan D, et al. The Smc5/6 complex restricts HBV when localized to ND10 without inducing an innate immune response and is counteracted by the HBV X protein shortly after infection. PLoS One. 2017;12:e0169648.

15. King TH, Kemmler CB, Guo Z, Mann D, Lu Y, Coeshott C, et al. A whole recombinant yeast-based therapeutic vaccine elicits HBV X, S and core specific $T$ cells in mice and activates human $T$ cells recognizing epitopes linked to viral clearance. PLoS One. 2014;9:e101904.

16. Crispe IN. The liver as a lymphoid organ. Annu Rev Immunol. 2009;27:147-63.

17. Thomson AW, Knolle PA. Antigen-presenting cell function in the tolerogenic liver environment. Nat Rev Immunol. 2010;10:753-66.

18. Huang $L R$, Wohlleber $D$, Reisinger $F$, Jenne $C N$, Cheng RL, Abdullah Z, et al. Intrahepatic myeloid-cell aggregates enable local proliferation of CD8(+) T cells and successful immunotherapy against chronic viral liver infection. Nat Immunol. 2013;14:574-83.

19. Cebula M, Riehn M, Hillebrand U, Kratzer RF, Kreppel F, Koutsoumpli G, et al. TLR9-mediated conditioning of liver environment is essential for successful intrahepatic immunotherapy and effective memory recall. Mol Ther. 2017;25: 2289-98.

20. Huang $L R, W u ~ H L$, Chen PJ, Chen DS. An immunocompetent mouse model for the tolerance of human chronic hepatitis B virus infection. Proc Natl Acad Sci U S A. 2006;103:17862-7.

21. Liao CW, Chen CA, Lee CN, Su YN, Chang MC, Syu MH, et al. Fusion protein vaccine by domains of bacterial exotoxin linked with a tumor antigen generates potent immunologic responses and antitumor effects. Cancer Res. 2005;65:9089-98.

22. Wu LL, Peng WH, Wu HL, Miaw SC, Yeh SH, Yang HC, et al. Lymphocyte antigen 6 complex, locus $\mathrm{C}^{+}$monocytes and Kupffer cells orchestrate liver immune responses against hepatitis B virus in mice. Hepatology. 2019;69:2364-80.

23. Zhu J, Chen H, Huang X, Jiang S, Yang Y. Ly6 $C^{\text {hi }}$ monocytes regulate T cell responses in viral hepatitis. JCI Insight. 2016;1:e89880.

24. Zhao HJ, Han QJ, Wang G, Lin A, Xu DQ, Wang YQ, et al. Poly I:C-based $r H B V$ vac therapeutic vaccine eliminates HBV via generation of HBV-specific CD8 ${ }^{+}$effector memory T cells. Gut. 2019;68:2032-43.

25. Lv S, Wang J, Dou S, Yang X, Ni X, Sun R, et al. Nanoparticles encapsulating hepatitis $B$ virus cytosine-phosphate-guanosine induce therapeutic immunity against HBV infection. Hepatology. 2014;59:385-94.

26. Chou HH, Chien WH, Wu LL, Cheng $\mathrm{CH}$, Chung $\mathrm{CH}$, Horng JH, et al. Agerelated immune clearance of hepatitis $B$ virus infection requires the establishment of gut microbiota. Proc Natl Acad Sci U S A. 2015;112:2175-80.

27. Rai D, Pham NL, Harty JT, Badovinac VP. Tracking the total CD8 T cell response to infection reveals substantial discordance in magnitude and kinetics between inbred and outbred hosts. J Immunol. 2009;183:7672-81.

28. Lin YJ, Wu HL, Chen DS, Chen PJ. Hepatitis B virus nucleocapsid but not free core antigen controls viral clearance in mice. J Virol. 2012;86:9266-73.

29. Kornyeyev D, Ramakrishnan D, Voitenleitner C, Livingston CM, Xing W, Hung $\mathrm{M}$, et al. Spatiotemporal analysis of hepatitis $B$ virus $\mathrm{X}$ protein in primary human hepatocytes. J Virol. 2019;93:e00248-19.

30. Kosinska AD, Moeed A, Kallin N, Festag J, Su J, Steiger K, et al. Synergy of therapeutic heterologous prime-boost hepatitis B vaccination with CpGapplication to improve immune control of persistent HBV infection. Sci Rep. 2019;9:10808

31. Li J, Ge J, Ren S, Zhou T, Sun Y, Sun H, et al. Hepatitis B surface antigen (HBsAg) and core antigen $(\mathrm{HBCAg})$ combine $\mathrm{CpG}$ oligodeoxynucletides as a novel therapeutic vaccine for chronic hepatitis B infection. Vaccine. 2015;33:4247-54.

32. Lee BO, Tucker A, Frelin L, Sallberg M, Jones J, Peters C, et al. Interaction of the hepatitis B core antigen and the innate immune system. J Immunol. 2009;182:6670-81.

33. Sitia G, Isogawa M, lannacone M, Campbell IL, Chisari FV, Guidotti LG. MMPs are required for recruitment of antigen-nonspecific mononuclear cells into the liver by CTLs. J Clin Invest. 2004;113:1158-67.

34. Sitia G, lannacone M, Aiolfi R, Isogawa M, van Rooijen N, Scozzesi C, et al. Kupffer cells hasten resolution of liver immunopathology in mouse models of viral hepatitis. PLoS Pathog. 2011;7:e1002061.

35. Guilliams M, Mildner A, Yona S. Developmental and functional heterogeneity of monocytes. Immunity. 2018:49:595-613.

36. Movita D, van de Garde MD, Biesta P, Kreefft K, Haagmans B, Zuniga E, et al. Inflammatory monocytes recruited to the liver within 24 hours after virusinduced inflammation resemble Kupffer cells but are functionally distinct. J Virol. 2015;89:4809-17.

37. De Koker S, Van Hoecke L, De Beuckelaer A, Roose K, Deswarte K, Willart MA, et al. Inflammatory monocytes regulate Th1 oriented immunity to $\mathrm{CpG}$ adjuvanted protein vaccines through production of IL-12. Sci Rep. 2017;7:5986. 
38. Nguyen KB, Salazar-Mather TP, Dalod MY, Van Deusen JB, Wei XQ, Liew FY, et al. Coordinated and distinct roles for IFN-alpha beta, IL-12, and IL-15 regulation of NK cell responses to viral infection. J Immunol. 2002;169:4279-87.

39. Bian Y, Zhang Z, Sun Z, Zhao J, Zhu D, Wang Y, et al. Vaccines targeting preS1 domain overcome immune tolerance in hepatitis B virus carrier mice. Hepatology. 2017;66:1067-82

40. Huang LR, Gabel YA, Graf S, Arzberger S, Kurts C, Heikenwalder M, et al. Transfer of HBV genomes using low doses of adenovirus vectors leads to persistent infection in immune competent mice. Gastroenterology. 2012; 142:1447-50 e3.

41. Tzeng HT, Tsai HF, Liao HJ, Lin YJ, Chen L, Chen PJ, et al. PD-1 blockage reverses immune dysfunction and hepatitis $B$ viral persistence in a mouse animal model. PLoS One. 2012;7:e39179.

\section{Publisher's Note}

Springer Nature remains neutral with regard to jurisdictional claims in published maps and institutional affiliations.

Ready to submit your research? Choose BMC and benefit from:

- fast, convenient online submission

- thorough peer review by experienced researchers in your field

- rapid publication on acceptance

- support for research data, including large and complex data types

- gold Open Access which fosters wider collaboration and increased citations

- maximum visibility for your research: over $100 \mathrm{M}$ website views per year

At BMC, research is always in progress.

Learn more biomedcentral.com/submissions 